\title{
Characteristics Mode Analysis of Modified Inset-fed Microstrip Antenna for Radio Frequency Energy Harvesting
}

\author{
Pradeep S. Chindhi', H. P. Rajani², G.B.Kalkhambkar ${ }^{3}$ and Rajashri Khanai ${ }^{4}$ \\ ${ }^{1,3}$ Sant Gajanan Maharaj College of Engineering, Kolhapur, India \\ ${ }^{2,4}$ KLE Dr. M.S. Sheshagiri College of Engineering and Technology Belagavi, India
}

\section{ABSTRACT}

In recent years the evolution of wireless communication has made it obligatory to develop compact, low weight antennas. In this research work, a modified inset fed antenna is presented for the Radio Frequency Energy Harvesting (RFEH). The antenna is designed, simulated, and optimized on FR-4 substrate of dielectric constant 4.3, loss tangent 0.025 , and height $1.6 \mathrm{~mm}$. The designed antenna operates in WiMAX middle band (3.2 GHz-3.8 GHz). It was found that the proposed antenna exhibits $|\mathrm{S} 11|$ of $-36.94 \mathrm{~dB}$ and attains the peak antenna gain and directivity of $2.63 \mathrm{dBi}$ and $5.97 \mathrm{dBi}$ at $3.328 \mathrm{GHz}$. The feed structure is modified for impedance matching, Voltage Standing Wave Ratio (VSWR) of 1.02, and characteristic impedance Z1,1 of $49.75 \mathrm{ohms}$ is attained at the frequency $3.328 \mathrm{GHz}$. Characteristics Mode Analysis (CMA) is performed to check the natural resonance of the designed antenna. The simulation results of Computer Simulation Technology (CST) is validated with IE3D software.

\section{KEY WORDS: CMA, DIRECTIVITY, GAIN, RF ENERGY HARVESTING, WIMAX.}

\section{INTRODUCTION}

Recently Internet of Things (IoT) is replacing humanto-human, human-to-machine communication. IoT empowers communication between device-to-device without any external involvement hence, furnish several challenges. These devices were operated by batteries which are replaceable and have restricted lifetime. The Radio Frequency (RF) energy can be collected from digital, analog RF sources such as Analog/Digital television, Broadcasting Stations (BS), FM and AM radio towers, Wireless Local Area Network (WLAN) access points, and mobile base stations (Munir et al. 2016). Inset-fed antenna with the defected ground for Long Range (LoRa)

\section{ARTICLE INFORMATION}

*Corresponding Author: pabcxyz4004@gmail.com

Received 7th Oct 2020 Accepted after revision 26th Dec 2020

Print ISSN: 0974-6455 Online ISSN: 2321-4007 CODEN: BBRCBA

Thomson Reuters ISI Web of Science Clarivate Analytics USA and Crossref Indexed Journal

\section{Clarivate
Analytics}

NAAS Journal Score 2020 (4.31)

A Society of Science and Nature Publication,

Bhopal India 2020. All rights reserved.

Online Contents Available at: http//www.bbrc.in/

Doi: $h t t p: / / d x$.doi.org/10.21786/bbrc/13.13/24 applications is given in (Pandey A \& Nair D 2019). High dielectric substrate inset fed Micro Strip Antenna (MSA) for GPS and C band applications is proposed in (Ahsan $\mathrm{M}$ et al. 2014).

In (Taha Bilal S. et al. 2018) inset fed microstrip patch antenna for RF energy harvesting over $2.45 \mathrm{GHz}$ is presented. The power ingesting of different household and personal devices and energy scavenging using a low-cost rectenna for the Internet of Things (IoT) applications was introduced (Shafique Kinza et al. 2018, Georgiou Orestis et al. 2016). Inset fed high gain 4-elements linear patch array was offered for IEEE802.11 standard (Ngobese B. W. \&t Kumar P. 2018). An inset-fed rectangular patch antenna using partial ground with an edge-cut method for the middle band WiMAX technology with enhanced bandwidth is developed in (Ndujiuba Charles U et. al. 2017). (Bakkali A et. al. 2016) presented a dual-band inset fed antenna for radio frequency energy scavenging systems in wireless sensors nodes operating at Wi-Fi bands $2.45 \mathrm{GHz}$ and $5 \mathrm{GHz}$. Dual-band Sierpinski carpet miniaturized microstrip patch antenna operable at 2.45 and $5.8 \mathrm{GHz}$ is constructed and simulated for RF energy harvesting (Shrestha Sika et. al. 2014).

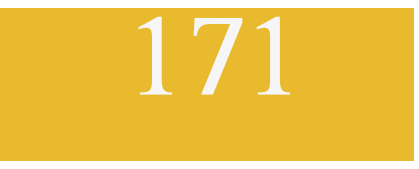


Spiral defected ground structure microstrip patch antenna with different fed techniques and performance of various antenna parameters is presented in (Elsheakh Dalia M \& Abdallah Esmat A. 2012). Different feeding methods has been studied in the past. The widely used feeding methods are Microstrip-Line Feed, Microstrip Inset-Feed, Coaxial Probe Feed, Aperture Coupled Feed, Proximity Coupling Feed, etc. (Balanis CA 2008, Bansal Aakash \&t Gupta Richa 2018).

In communication systems, there are numerous types of MSA that can be used for different applications. In this paper, a modified inset fed rectangular MSA is introduced for the RF energy scavenging. A modified inset fed rectangular MSA is simulated using 3D EM simulation, and the results are interpreted for modified inset feed. The modified inset feed is adjusted to attain higher directivity and gain with $50 \Omega$ impedance matching. Finally the observations are provided in the conclusion.

\section{MATERIAL AND METHODS}

Characteristics mode analysis: The theory of CMA was first presented in (R Garbacz \& $R$ Turpin 1971) and then revisited in (Harrington R. F. and Mautz J. R. 1971). The CMA offers the probable point of resonance, distribution of surface current and the pattern of antenna (Huang S.et al 2018, Chen Y. and Wang C.F. 2014). The CMA is broadly explained in (Cabedo-Fabres M. et al. 2007,
Maximidis R. T. et al. 2014) for the Perfect Electric Conductor (PEC). CMA is performed to give added insights into different modes on the antenna operation. CMA is entirely dependent on the radiating structure, material irrespective of feed type. CMA is derived from the impedance matrix and evaluating the eigenvalue problem (Sohrabi Atefeh et al. 2019).

$$
\begin{aligned}
& Z=R+j X \\
& X J_{n}=\lambda_{n} R J_{n}
\end{aligned}
$$

Where

$\mathrm{R}$ is Hermitian Real part of $\mathrm{Z}$ matrix

$\mathrm{X}$ is Hermitian Imaginary part of $\mathrm{Z}$ matrix.

$\mathrm{Jn}$ is eigencurrent and $\lambda \mathrm{n}$ represents eigenvalue

Parameters that can be considered for CMA are:

Modal Significance (MS): MS has its maximum value as 1. MS helps in identifying the resonant frequency of modes and it is computed by equation (iii):

$$
M S=\left|\frac{1}{1+j \lambda_{n}}\right|
$$

Characteristic Angle ( $\alpha$ ): Characteristic Angle (CA) specifies the presence of resonance mode, and is premeditated by equation (iv):

\begin{tabular}{|c|c|c|c|c|c|c|c|c|c|c|c|c|}
\hline Dimensions in (mm) & $\mathrm{Wg}$ & $\mathrm{Lg}$ & Ws & Ls & Wp & $\mathrm{Lp}$ & Wf & Lf & W1 & $\mathrm{H} 1$ & ws & ls \\
\hline Values & 44 & 41 & 44 & 41 & 24 & 21 & 3.0 & 15.20 & 1.0 & 5.2 & 0.5 & 1.5 \\
\hline
\end{tabular}

$$
\begin{aligned}
& \alpha_{n}=180^{\circ}-\tan ^{-1}\left(J_{n}\right) \\
& \text { At resonance, } \lambda_{n}=0 \text { and } \alpha_{n}=180^{\circ}
\end{aligned}
$$

Modal study of proposed antenna: A quadrilateral patch antenna is first intended to resonate at the desired band, which is $3.2 \mathrm{GHz}$ to $3.8 \mathrm{GHz}$. The designed antenna in CST gave a resonance at $3.364 \mathrm{GHz}$ with $\mathrm{S} 11$ of $-16 \mathrm{~dB}$ as given in [Figure. 1(a)] and [Figure. 1(b)]. To improve the behavior of the designed antenna we performed a modal study of this antenna by observing 180 degrees crossing point of first 3 modes on characteristics angle. Mode 1 and mode 2 are resonant at the desired band whereas mode 3 is resonating beyond $4 \mathrm{GHz}$, therefore, mode 1 and mode 2 are dominant in the desired band as observed in [Figure. 1 (c)]. The modal current distribution of mode 1 and mode 2 are carefully observed to study the density of current which is responsible for resonance as given in [Figure. 2], first row in [Figure. 2] shows mode 1 current distribution at the desired band of frequencies and second row in [Figure. 2] shows mode 2 current distribution at the desired band of frequencies.

It is observed that in mode 1 as well as in mode 2 current on feedline and inset dept is significant which clears that changes in inset depth may give an improved resonance. Taking this into consideration the inset depth is modified at [Figure. 3 (a)] to arrive at an improved S11 parameters from $-16 \mathrm{~dB}$ to -36.755983 improvement in gain and directivity is also observed. In the modified geometry it is noticed that the modal current on the left-hand side of inset depth is controlled by Mode 1 [Figure..3 (b)] and right-hand side of inset depth is controlled by mode 2 [Figure. 3 (c)] Thus by iteratively tuning the inset depth of antenna we observed the improved performance.

The characteristic angle, eigenvalue, and modal significance of the modified antenna are studied in [Figure. 4.] Mode 1 crosses 180 degrees line on characteristics angle plot at $3.332 \mathrm{GHz}$ with eigenvalue of 0.0008 and modal significance of 0.99999 , mode 2 resonates at $3.496 \mathrm{GHz}$ with the eigenvalue of 0.0004 and modal significance of 0.999999 whereas mode 3 resonates at $4.14 \mathrm{GHz}$ with eigenvalue of 0.0005 and modal significance of 0.999998 . But since mode 3 resonates beyond the considered band of $3.2 \mathrm{GHz}$ to 3.8 $\mathrm{GHz}$ it is least significant. The dimensional details of the antenna are discussed in next section. ws \& ls refers the slot width and length at inset fed. 
Figure 1: Rectangular patch, its S11 parameter and characteristics angle

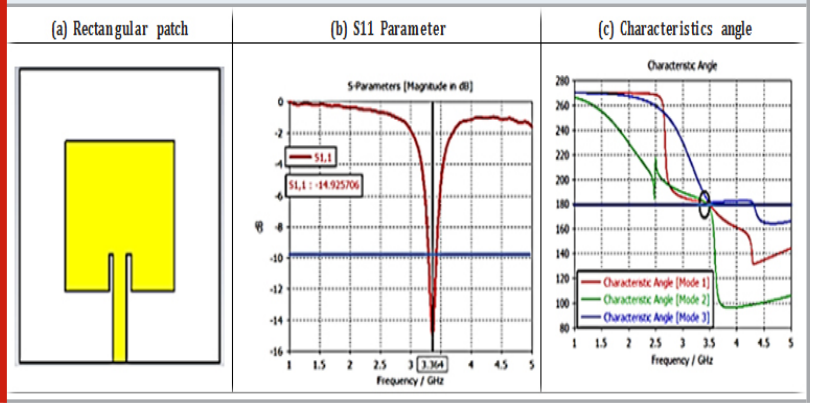

Figure 2: Modal current in mode 1 (Row 1) and mode 2 (Row 2)

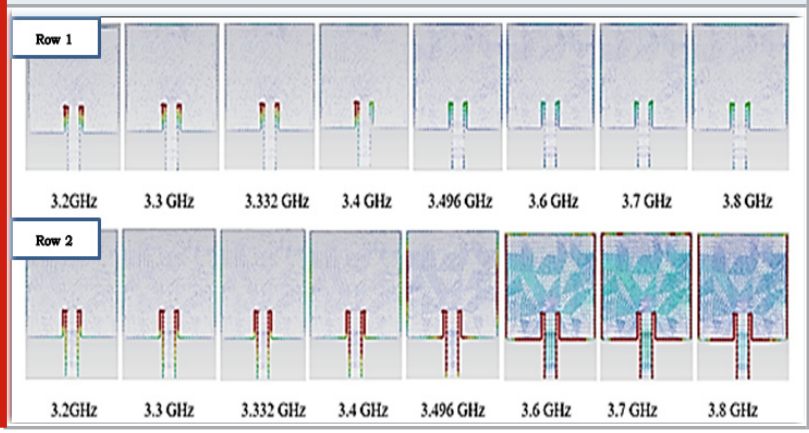

Figure 3: Modified rectangular patch modal current distribution

\begin{tabular}{|l|l|l|l|}
\hline \multicolumn{1}{|c|}{ (a) Modified geometry } & (b) Mode 1 current at 3.328G & (c) Mode 2 current at 3.328 $\mathrm{GHz}$ \\
\hline & & & \\
\hline
\end{tabular}

Figure 4: Modal analysis of modified inset fed geometry

(a) Characteristics angle

Design of modified inset feed MSA: There are three important design parameters to be considered while designing a rectangular MSA. These are: frequency of resonance (f_r), substrate dielectric constant ( $\varepsilon r$ ) and the height of the dielectric substrate (h), (Balanis CA 2008). The schematic of the modified inset feed rectangular MSA is simulated in 3D EM simulation software as given in [Figure 5 (a) and (b)]. The projected antenna structure makes use of an FR-4 substrate of the relative permittivity of 4.3. The detail dimensions of the antenna are given in [Table l] which are used for the simulation.

Figure 5: (a) Proposed Antenna

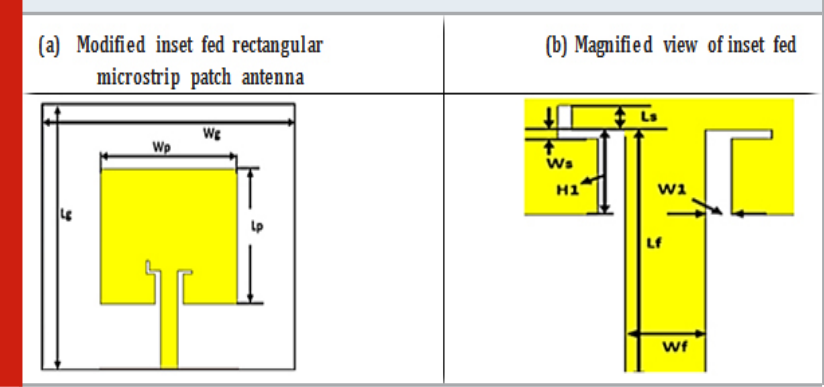

\section{RESULTS AND DISCUSSION}

Simulation, parametric study: The impact of modified inset feed on S-Parameters (S11), characteristic impedance (Z11), surface current distribution, far-field directivity (in $\mathrm{dB}$ ) and gain is investigated. The rectangular MSA is delicate to feed location and feed techniques. The design geometry of the proposed rectangular patch antenna and modified inset fed patch is as shown in [Figure 6]. The effect of inset and modified inset fed on reflection coefficient S11, surface current distribution and Impedance $\mathrm{Z} 1$ is observed.

Figure 6: Iterations of design geometry

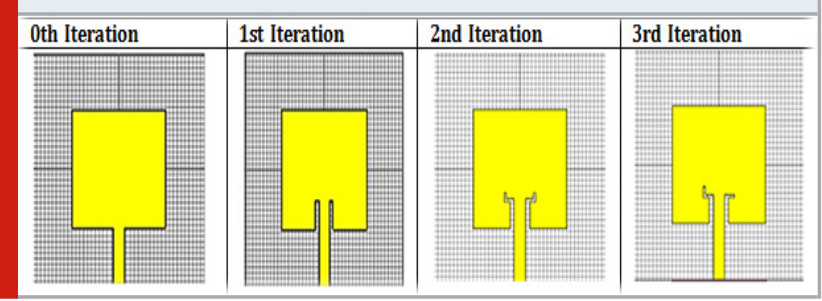

Figure 7: Simulated surface current distribution for the Iteration 0 to 3

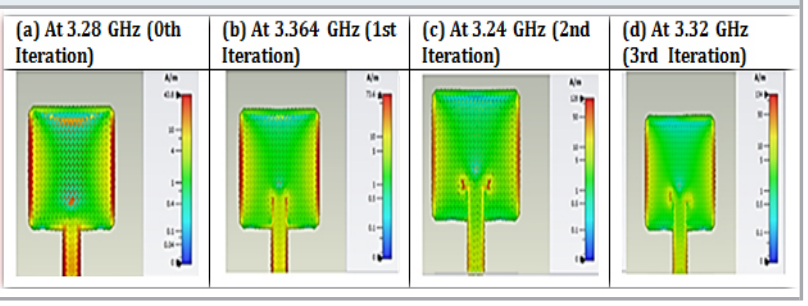

The simulated surface current distribution of the proposed antennas at different frequencies 3.28, 3.364, 3.24, and $3.32 \mathrm{GHz}$ are shown [Figure 7]. Surface current at each frequency is obtained at $3.28 \mathrm{GHz}$ (0th Iteration), the optimum distribution of surface current is on the edge (along the length) of the antenna and on the fed line as shown in [Figure 7 (a)]. Similarly, at $3.364 \mathrm{GHz}$ (1st Iteration) with inset fed the current distribution is on edge (along the length) and part of the current is on the fed line. At $3.24 \mathrm{GHz}$ (2nd Iteration), the surface current 
is mainly distributed on the edge (along the length), feed line and at modified inset fed. At $3.32 \mathrm{GHz}$ (3rd Iteration) the part of the surface current is distributed on the edge

Figure 8: Simulated S11 $(\mathrm{dB})$ versus frequency for the Iteration 0 to 3

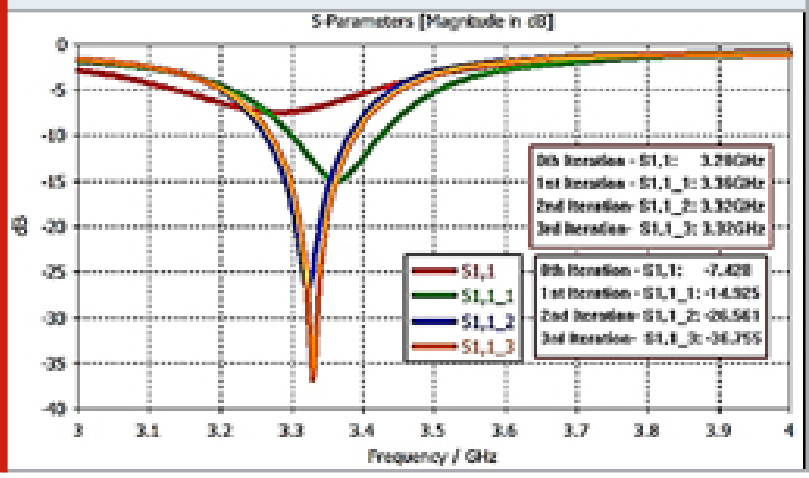

Figure 10: Smith chart

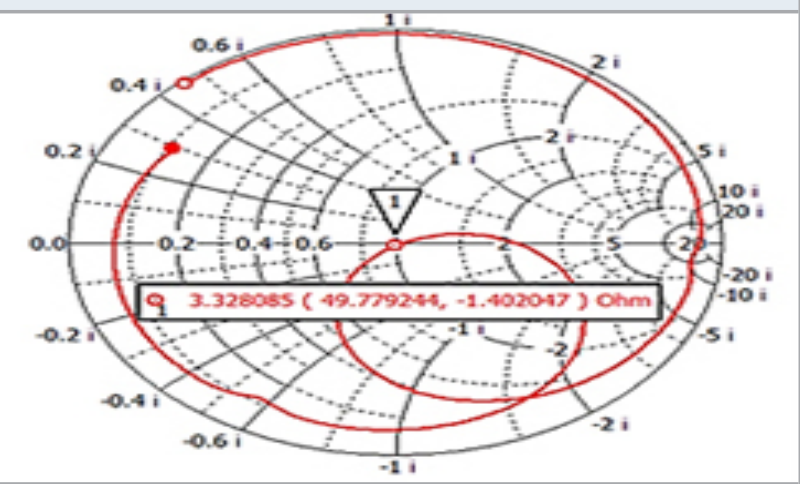

Figure 12: Radiation pattern at frequencies $3.328 \mathrm{GHz}$ ((3rd Iteration))

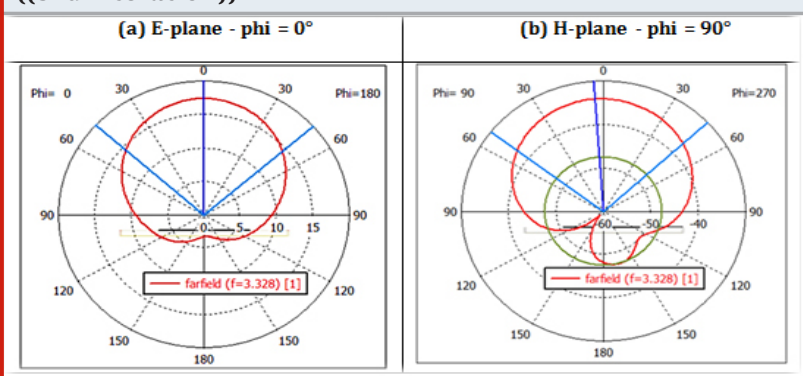

(along the length), feed line, at modified inset fed, and towards the center of the rectangular patch.

Figure 9: Simulated VSWR versus frequency for the Iteration 0 to 3

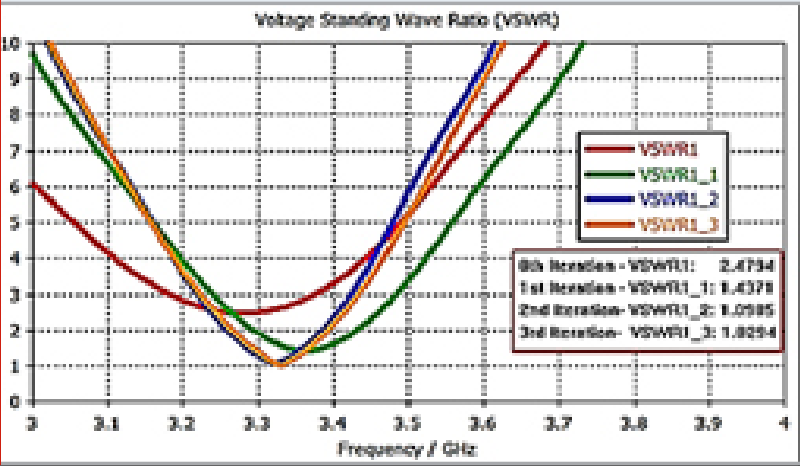

Figure 11: Gain and Directivity at $3.328 \mathrm{GHz}$ (3rd Iteration

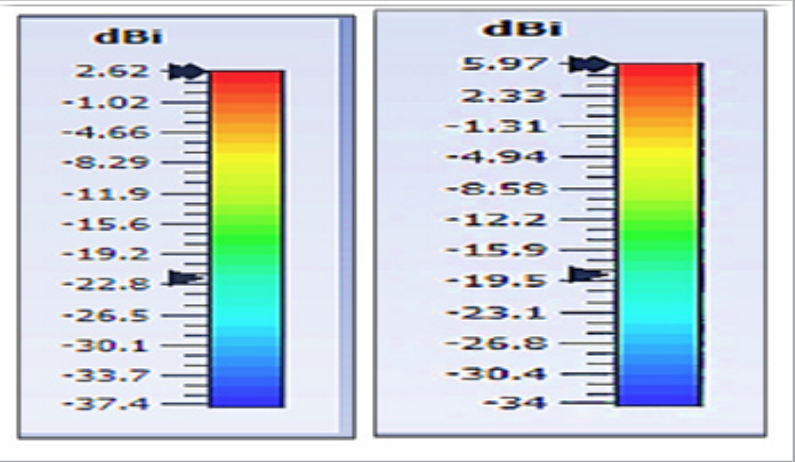

Figure 13: Validation of S11in CST and IE3D

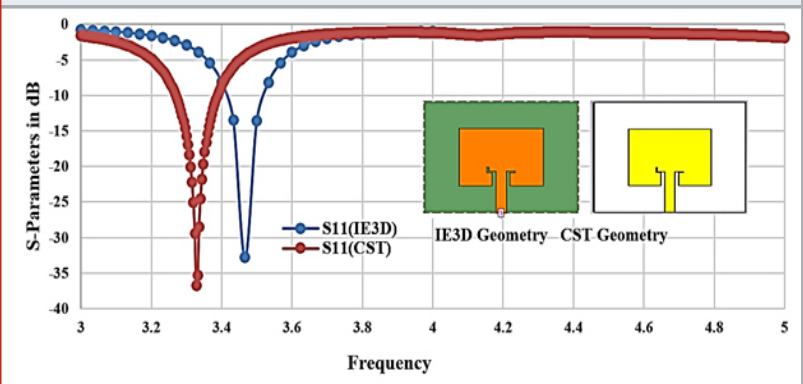

Table 2. Comparison of performance parameters

\begin{tabular}{|l|c|c|c|c|}
\hline \multirow{2}{*}{$\begin{array}{l}\text { EM } \\
\text { Software }\end{array}$} & $\begin{array}{c}|c| \\
\text { Resonance frequency } \\
(\mathrm{GHz})\end{array}$ & $|\mathrm{S} 11|$ & $\begin{array}{c}\text { Gain } \\
(\mathrm{dBi})\end{array}$ & $\begin{array}{c}\text { Directivitya } \\
(\mathrm{dBi})\end{array}$ \\
\cline { 2 - 5 } & 3.328 & -36.755983 & 2.63 & 5.97 \\
\hline CST & 3.466 & -32.833922 & 3.54 & 6.57 \\
\hline IE3D & & &
\end{tabular}


Table 3. Comparison of praposed wok with existing literature

\begin{tabular}{|l|c|c|c|c|}
\hline Ref. & $\begin{array}{c}\text { Resonance } \\
\text { frequency (GHz) }\end{array}$ & $|\mathrm{S} 11|$ & $\begin{array}{c}\text { Dimensions } \\
(\mathrm{mm})\end{array}$ & $\begin{array}{c}\text { Type of } \\
\text { substrate }\end{array}$ \\
\hline 12 & 4.0 & -21.00 & 30 X35X1.905 & Ceramic-PTFE \\
\hline 25 & 2.45 & -20.91 & 46 X37X1.524 & FR-4 \\
\hline 20 & 3.7 & -21.16 & $70 X 70 X 1.6$ & FR-4 \\
\hline 04 & 2.45 & -28.00 & 111.3 X111.3X1.6 & FR-4 (Lossy) \\
\hline Proposed design & 3.328 & -36.755983 & $44 X 41 X 1.6$ & FR-4 (Lossy) \\
\hline CST & 3.466 & -32.833922 & & \\
\hline
\end{tabular}

This indicates that modification of the inset line feed, controls the resonant frequency of the antenna. The [Figure 8] shows the effect of inset and modified inset fed on resonance frequency and reflection coefficient (S11). There is a deviation in resonance frequency and reflection coefficient (S11). The VSWR characteristics for iteration 0 to 3 are displayed in [Figure 9]. It can be observed that for modified inset slot length and inset slot width (3rd Iteration) ws $=0.5 \mathrm{~mm}$ and $\mathrm{ls}=1.5 \mathrm{~mm}$, the VSWR of 1.02 is attained at the frequency $3.328 \mathrm{GHz}$ and impedance $\mathrm{Z} 1,1 \_3=49.75 \mathrm{ohm}$ as shown in [Figure 10].

Validation of Results: According to (Pozar David M. et al. 2000, A Guy et. al. 2009) IE3D gives more accurate results with slightly longer simulation time. IE3D is based on Method-of Moments (MOM) and CST Microwave Studio (CST MWS) works with the Finite Integration Technique (FIT). The [Fig. 14] shows the simulated |S11| plot, and geometry in IE3D and CST. [Table 2] shows the comparison of $|\mathrm{S} 11|$, Gain and Directivity. According to Friis transmission formula for RF energy harvesting high gain antenna are required (Kraus JD et al. 2006). From the [Table 2], it is evident that the antenna geometry presented in the paper is suitable for RF energy harvesting.

The table 3 shows the comparison of presented work with the recent literature's. The proposed design is compact and gives better performance in terms of $|\mathrm{S} 11|$ characteristics.

\section{CONCLUSION}

A modified inset fed MSA is simulated. The modified inset fed rectangular MSA functions in WiMAX middle band frequencies ranging from $3.27 \mathrm{GHz}$ to $3.38 \mathrm{GHz}$ with the substrate depth of $1.6 \mathrm{~mm}$. The peak gain and directivity at $3.328 \mathrm{GHz}$ are $2.63 \mathrm{dBi}$ and $5.97 \mathrm{dBi}$. The results suggest that the proposed antenna construction is suitable for RF energy harvesting in the WiMAX band. Impedance matching is a challenging task in designing MSA, Several methods have been introduced in the past, such as stub matching, quarter-wave transformer, multi section transformer, taper lines and by lumped elements like capacitor and inductor etc. In this paper, we have introduced the simplest technique of impedance matching by modifying the feed structure which improves the S11 characteristics and thus helps in achieving the required gain and directivity for the RF energy harvesting.

\section{REFERENCES}

A Guy at. al. (2009), A Practical Guide to 3D Electromagnetic Software Tools. Katholieke Universiteit Leuven, Belgium, IEEE Antennas Propagat. Magazine, Vol, 51, No. 1, pp. 23-38.

Ahsan M et al. (2014), Compact Double-P Slotted Inset-Fed Microstrip Patch Antenna on High Dielectric Substrate. Hindawi Publishing Corporation, The Scientific World Journal, Volume 2014, Article ID 909854,6pages, http://dx.doi.org/10.1155/2014/909854.

Balanis CA (2008), Antenna theory, analysis and design. Wiley, New York. ISBN: 0-471-66782-X.

Bakkali Aet al. (2016), A Dual-Band Antenna for RF Energy Harvesting Systems in Wireless Sensor Networks. Hindawi Publishing Corporation Journal of Sensors, Volume 2016, Article ID 5725836, 8 pages http://dx.doi.org/10.1155/2016/5725836.

Bansal Aakash \&t Gupta Richa (2018) A review on microstrip patch antenna and feeding techniques. Int. j. inf. tecnol. https://doi.org/10.1007/s41870-018-0121-4. Received: 27 April 2017 / Accepted: 28 February 2018.

Cabedo-Fabres M. et al. (2007), The theory of characteristic modes revisited: A contribution to the design of antennas for modern applications. IEEE Antennas Propag. Mag., vol. 49, no. 5, pp. 52-68, Oct. 2007.

Chen Y. and Wang C.F. (2014), Electrically small UAV antenna design using characteristic modes. IEEE Trans. Antennas Propag., vol. 62, no. 2, pp. 535_545, Feb. 2014.

Elsheakh Dalia M \& Abdallah Esmat A. (2012), Different Feeding Techniques of Microstrip Patch Antennas with Spiral Defected Ground Structure for Size Reduction and Ultra-Wide Band Operation. Journal of Electromagnetic Analysis and Applications, 4, 410-418 http://dx.doi. 
org/10.4236/jemaa.2012.410056 (http://www.SciRP.org/ journal/jemaa.

Georgiou Orestis et al. (2016), How Many Wi-Fi APs Does it Take to Light a Lightbulb?. Received April 13, 2016, accepted May 16, 2016, date of publication May 26, 2016, date of current version August 4, 2016. Digital Object Identifier 10.1109/ACCESS.2016.2573681.

Harrington R. F. and Mautz J. R. (1971), Theory of characteristic modes for conducting bodies. IEEE Trans. Antennas Propag., vol. 19, no. 5,pp. 622-628, Sep. 1971.

Huang S.et al (2018), Study on the relationships between eigenmodes, natural modes, and characteristic modes of perfectly electric conducting bodies. Int. J. Antennas Propag., vol. 2018, Apr. 2018, Art. no. 8735635.

K Sudeep D \& Kumaraswamy r. H.V. (2019), A Dual Band Microstrip Patch Antenna for RF Energy Harvesting. International Journal of Engineering Research \& Technology (IJERT) http://www.ijert.org ISSN: 22780181, IJERTV8IS060055. Vol. 8 Issue 06, June-2019. Kraus JD et al. (2006), Antennas and Wave Propagation. New Delhi: Tata McGrawHill Education; 2006:906.

Maximidis R. T. et al. (2014) Characteristic mode analysis of composite metal dielectric structure, based on surface integral equation/moment method," in Proc. IEEE Eur. Conf. Antennas Propag. (EuCAP), Hague, The Netherlands, Apr. 2014, pp. 2822_2826.

Munir et al. (2016), Optimization and analysis of WLAN RF energy harvesting system architecture. International Symposium on Wireless Communication Systems (ISWCS), pp. 429-433, 0ct.

Ndujiuba Charles U et al (2017), Bandwidth Enhancement of An Inset-Fed Rectangular Patch Antenna using Partial Ground with Edge-cut Method. International Journal of Electromagnetics and Applications,7(1):9-16 DOI: 10.5923/j.ijea.20170701.02.

Ngobese B. W. \& Kumar P. (2018), A High Gain
Microstrip Patch Array for $5 \mathrm{GHz}$ WLAN Applications Advanced Electromagnetics. Vol. 7, No. 3.

Pandey A \& Nair D (2019) Inset Fed Miniaturized Antenna with Defected Ground Plane for LoRa Applications. Third International Conference on Computing and Network Communications (CoCoNet'19).

Pozar David M. et al. (2000), A Comparison of Commercial Software Packages for MSA Analysis. 0-7803-6369-8/00/\$10.00 02000 IEEE.

Rajawat Asmita \&t Singhal P. K. (2018), Design and implementation of a Dual Band Rectifier Antenna for Efficient RF Energy Harvesting in Wireless Sensor Networks. Journal of Circuits, Systems, and Computers, doi: 10.1142/S0218126619500348.

R Garbacz \& R Turpin (1971), A generalized expansion for radiated and scattered fields. IEEE Trans. Antennas Propag.19, (3), pp. 348-358.

Shafique Kinza et al. (2018), Energy Harvesting Using a Low-Cost Rectenna for Internet of Things (IoT) Applications. Received April 1, 2018, accepted April 29, 2018, date of publication May 8, 2018, date of current version June 26, 2018. Digital Object Identifier 10.1109/ ACCESS.2018.2834392.

Shrestha Sika et al. (2014), A New Fractal-Based Miniaturized Dual Band Patch Antenna for RF Energy Harvesting. Hindawi Publishing Corporation International Journal of Antennas and Propagation Volume 2014, Article ID 805052, 9 pages http://dx.doi. org/10.1155/2014/805052.

Sohrabi Atefeh et al. (2019), Design and analysis of a Broadband electrically small antenna using characteristic mode theory. International Journal of Electronics and Communications, doi: https://doi. org/10.1016/j.aeue.2019.152991.

Taha Bilal S. et al. (2018), Simulating of RF energy harvesting micro- strip patch antenna over $2.45 \mathrm{GHZ}$. International Journal of Engineering \& Technology, 7 (4) (2018) 5484-5488, doi: 10.14419/ijet.v7i4.27031. 